\title{
A Economia Política de John Maynard Keynes: de Versalhes à Grande Depressão
}

\section{The Political Economy of John Maynard Keynes: from Versailles to Great Depression}

Resumo: O presente artigo tem por objetivo analisar, ao longo do período histórico que se inicia no imediato pós-Primeira Guerra Mundial e termina após a eclosão da Grande Depressão, o posicionamento de Keynes, no que tange às suas considerações sobre economia, sempre efetuadas com a intenção de causar algum impacto na esfera política. Assim, partimos do Tratado de Versalhes, passamos pela discussão do retorno ao padrão ouro e terminamos por abordar a Grande Depressão, período com o qual se identifica a interpretação usual de Keynes como o autor da Teoria Geral, ou seja, teórico da economia da depressão.

Palavras-chave: Keynes. Economia política. História do pensamento econômico.

Abstract: This paper analyses, over the historical period that begins in the immediate post-First World War and ends after the outbreak of the Great Depression, the posture of Keynes, in regard to their considerations about economics, always made with intent to cause any impact in the political sphere. Thus, begins with the Treaty of Versailles, passing by the discussion over the return to the gold standard, and finishes approaching the Great Depression, period identified with the usual interpretation of Keynes as the author of The General Theory, namely, theorist of the economics of depression.

Keywords: Keynes. Political economy. History of economic thought.

JEL Classification: B31; E12.

\footnotetext{
* Professor da Universidade Federal do Rio Grande do Norte (UFRN). E-mail: fabriciopleite@ufrnet.br

O autor agradece a Frederico Mazzucchelli, pelas entusiásticas exposições acerca do período histórico aqui trabalhado, e a Eduardo Angeli, Gustavo Aggio e Lucas Teixeira, pelas sugestões sobre versões anteriores deste trabalho. Também agradece a um parecerista anônimo pelas considerações. Agradece, ainda, ao suporte financeiro da Capes, concedido na forma de bolsa de doutoramento, no período em que o presente artigo tomava forma.
} 


\section{1 lntrodução}

O presente artigo tem por objetivo analisar, ao longo do período histórico que se inicia no imediato pós-Primeira Guerra Mundial, e que termina após a eclosão da Grande Depressão, o posicionamento de Keynes no que tange às suas considerações sobre economia, sempre efetuadas com a intenção de causar algum impacto na esfera política. ${ }^{1}$ Assim, partimos do Tratado de Versalhes, em torno do qual gira As consequências econômicas da paz, passamos pela discussão do retorno ao padrão ouro, para que a leitura de $A$ tract on monetary reform se faz imprescindivel, e terminamos por abordar a Grande Depressão, ocasião em que o instrumental presente em $A$ treatise on money foi largamente utilizado. Deve-se também a este último evento a interpretação usual de Keynes como o autor da Teoria Geral, ou seja, teórico da economia da depressão.

A ligação entre os escritos de fins dos anos 1920 e o arcabouço teórico da Teoria Geral, apesar de não constituir o objetivo essencial deste artigo, é brevemente traçada ao longo da seção referente à Grande Depressão, com o apoio de textos do início dos anos 1930 que abordavam saídas para a mesma. É a partir da apreciação dos escritos de Keynes frente a eventos históricos selecionados que o presente artigo busca alicerçar seus posicionamentos políticos e pontos teóricos particulares, e não o contrário, como é o caso de alguns estudos que tratam, por exemplo, da evolução do pensamento de Keynes rumo à Teoria Geral por meio dos diversos rascunhos atinentes à mesma. Assim, a despeito de não pretendermos estabelecer a evolução cronológica das concepções teórico-analíticas de Keynes, algo nesse sentido acaba por ser colateralmente atingido.

Além desta primeira seção introdutória, o artigo é subdividido justamente pelos eventos históricos selecionados: a segunda seção versa sobre as negociações em torno do Tratado de Versalhes, a terceira seção trata do debate concernente ao retorno ao padrão ouro e a quarta seção aborda a Grande Depressão. Segue-se, ainda, uma quinta seção, contendo notas sobre o conceito de economia política, ao qual as seções anteriores somente fazem menção. Para finalizar, seguem algumas considerações finais.

\section{Tratado de Versalhes}

As principais negociações acerca das reparações de guerra, na Conferência de Paris, após serem iniciadas com um grupo dos dez países mais influentes à época, ficaram restritas ao chamado Conselho dos Quatro, composto por Estados

De acordo com Dillard (1946, p. 126-127), é esse comprometimento com a possibilidade de mudança dada pela vitória das ideias frente aos interesses escusos que faz com que Keynes sempre esteja com um plano, um acordo ou uma reforma à mão para resolver os problemas da ocasião. 
Unidos, França, Grã-Bretanha e Itália, e representado pelas figuras de Wilson, Clemenceau, Lloyd George e Orlando, respectivamente. A participação de Keynes como representante do Tesouro Britânico nesse conselho - a qual fora posteriormente colocada à prova e reafirmada pelo próprio ${ }^{2}-$, apesar de não ter logrado o êxito político pretendido à época, levando inclusive à sua retirada precoce das negociações, resultou no relato de As consequências econômicas da paz, o qual lhe rendera, além de grande notoriedade, alguma influência nas decisões para depois de Paris. Tal relato, após considerações gerais sobre as condições vigentes na Europa do pré-guerra, trata de descrever as personalidades dos envolvidos nas negociações, especialmente Wilson e Clemenceau, e como tais características moldaram o resultado final do Tratado de Versalhes.

Como se tornou evidente, as negociações da Conferência de Paris, que culminaram no Tratado de Versalhes, falharam em estabelecer um acordo de paz duradouro e acabaram por exaltar os ânimos mais nacionalistas na Europa continental, o que dá margem para a interpretação do entre-guerras como o armistício para 20 anos profetizado pelo Marechal Foch (MAZZUCCHELLI, 2009, p. 315), sendo que a assinatura do Tratado de Versalhes por parte da Alemanha, em 28 de junho de 1919, ao invés de constituir o marco do início da paz, significou um reconhecimento temporário de submissão e o decorrente acirramento das tensões visando a reversão desse quadro.

Conforme enfatizado por Henig (1995), encontrávamo-nos numa circunstância singular da história na qual o peso da imprensa escrita sobre a opinião pública começara a se fazer presente, reportando também cada etapa das negociações pelas reparações. Desse modo, havia se tornado pouco provável uma resposta diferente por parte de Lloyd George, o qual se elegera nas bases de um acordo que se mostrasse punitivo para a Alemanha e se afastasse do ideal wilsoniano. Antes de adentrar a seara das reparações estritamente, também Keynes (1971c) faz uma análise acerca da plataforma de campanha de Lloyd George, de como ocorreu a transformação desta rumo a um discurso cada vez mais revanchista, e, portanto, sob que desígnios este se dirigira à Conferência de Paris.

O próprio Keynes (1972) faz um reconhecimento a posteriori, apesar de discordar totalmente do resultado final de Versalhes e fazer oposição enquanto pôde à representação do primeiro ministro britânico, argumentando que foi feito o possível para aquele dado momento, uma vez que as paixões e ignorâncias do grande público jogam um papel relevante num mundo que aspira a democracia (KEY-

$2 \quad$ Consultar o capítulo What really happened at Paris, volume XVII, dos Collected Writings, no qual há referências a um artigo do professor Haskins, publicado no The Times de maio de 1921, que afirma, com base em declarações do capitão Paul Mantoux (intérprete oficial das reuniões do Conselho dos Quatro), que Keynes nunca esteve presente numa seção regular de tal conselho. Seguem, no referido capítulo, as respostas do próprio Keynes. 
NES, 1972, p. 33). A democracia, diga-se de passagem, não era para Keynes um bem em si mesmo - como já era pretensamente para os norte-americanos, cuja própria entrada na Primeira Guerra representava uma cruzada pela democracia (HENIG, 1995, p. 10) -, mas teria essa terrível falha congênita de relegar decisões cruciais a paixões momentâneas, a qual uma clara hierarquização na esfera política - desde que primasse pela razão - não estaria suscetível. ${ }^{3}$

Acerca das reparações, nos relata ainda Henig (1995, p. 20-26) a tentativa de Keynes de persuadir Lloyd George, argumentando que a recuperação econômica da Inglaterra dependia sobremaneira do comércio internacional, para que seria crucial o reerguimento da Alemanha, grande parceira comercial de outrora. Vale notar, desde já, que tal dependência do comércio internacional a partir da recuperação da Alemanha deve ser entendida pela necessidade da existência de um mercado externo capaz (i.e., com renda suficiente) de trazer receitas de exportação à Inglaterra. Também os representantes norte-americanos, face as vultosas quantias emprestadas aos Aliados, as quais acreditava-se que somente poderiam ser pagas a partir das quitações alemãs de reparação, ${ }^{4}$ defenderam um esquema que levasse em conta a capacidade de pagamento da Alemanha, não sufocando sua economia. Todavia, e mesmo com a finalidade de deixar clara a natureza da dívida alemã, foi incluída no Tratado de Versalhes uma cláusula que atribuía à Alemanha toda a responsabilidade sobre as perdas sofridas pelos Aliados, ainda que para fins de pagamento valessem mormente os danos provocados a civis.

O que Lloyd George e o Presidente Wilson falharam em captar, ou pelo menos em levar às últimas consequências, é que a questão em relevo não era fundamentalmente de cunho político ou territorial - de fronteiras ou soberanias nacionais -, mas de natureza econômico-financeira: a ameaça à organização europeia estava relacionada com alimentos, matérias-primas, carvão, ferro, transporte, etc. ${ }^{5}$ No fundo, as estimativas da capacidade de pagamento das reparações deveriam levar mais em conta tais determinações do que as primeiras (KEYNES, 1971c).

Naturalmente, Clemenceau não estava disposto a afrouxar os termos de pagamento pelas reparações, e, quando a pressão política sobre Lloyd George chegou a tal ponto que lhe foi enviado um telegrama com 376 signatários membros do parlamento, em abril de 1919, clamando para que a fatura completa fosse

3 Sobre o tópico da democracia em Keynes, ver Fitzgibbons (1990, p. 170-173), que também situa a plataforma eleitoral de Lloyd George como baseada na vingança contra a Alemanha.

4 Esse princípio, aliás, constituía a base da chamada Balfour note, de 1925, também duramente criticada por Keynes (1972).

5 Em 1929, já com um olhar retrospectivo, Keynes (1983, p. 351, tradução nossa) reafirma que o pior problema da Europa a partir de 1919 não era oriundo da destruição causada pela guerra: "[...] o problema era um problema de desorganização; o problema do esgotamento dos estoques de comida e matéria-prima, e do colapso do crédito [...]. Além do mais, a organização normal do transporte e do comércio, através da qual os produtos poderiam ser conduzidos para onde fossem mais procurados, tinha desmoronado". 
apresentada aos alemães, parecia inevitável um acordo contrário aos apelos pela racionalidade feitos por Keynes. Entretanto, o que sucedeu foi uma procrastinação da decisão acerca dos valores exatos da reparação, constituindo-se uma comissão específica para que esses valores fossem estabelecidos (e revistos à luz do desenrolar dos acontecimentos) nos anos subsequentes e deixando aos alemães a incômoda e arrazoada percepção de que os Aliados tinham lhes proposto a assinatura de um cheque em branco. As cifras, que sempre giraram em torno de valores bem acima dos tetos sugeridos por Keynes, foram gradativamente sendo reduzidas e, apesar de, em 1921, ainda corresponderem ao quádruplo da recomendada por ele, tornaram-se menos punitivas ${ }^{6}$ e levaram-no a reconhecer que, na prática, o tratado foi mais brando do que pintara em sua interpretação literal realizada no calor do debate (KEYNES, 1972). Uma execução mais branda, entretanto, não pode ser interpretada como uma prova contrária às preocupações de Keynes, uma vez que as diversas cláusulas punitivas à Alemanha já haviam sido colocadas e as animosidades já estavam profundamente instauradas.

Pelo clima presente em diversas cartas datadas dos primeiros dias de junho de $1919,{ }^{7}$ pode-se notar que as negociações tinham exaurido as forças de Keynes. Um "absoluto esgotamento nervoso", é como o próprio descreve seu estado numa carta enviada à sua mãe em primeiro de junho (KEYNES, 1971b, p. 470). Tal esgotamento o fez sair do hotel em que se encontrava e procurar uma estadia mais tranquila, permanecendo quase todo o tempo prostrado na cama nos dias seguintes, e não retornando à Inglaterra nessa ocasião por atender aos apelos do General Smuts, que o disse que "alguém só pode deixar o campo de batalha morto" (KEYNES, 1971b, p. 470, tradução nossa). Finalmente, em 5 de junho, em carta de um parágrafo dirigida ao primeiro ministro Lloyd George, informa que deixará aquela "cena de pesadelo" em que tinham se transformado as negociações por não poder fazer "nada mais de bom" ali. A batalha estava perdida, declarou (KEYNES, 1971b, p. 469, tradução nossa).

Keynes advogara firmemente a favor da revisão do Acordo de Versalhes, revendo as cifras que considerava incompatíveis com o reerguimento da Alemanha e que acarretariam, segundo ele, a piora das condições econômicas e sociais em toda a Europa (KEYNES, 1972). Propusera, ainda, o valor de 2 bilhões de libras (KEYNES, 1972, p. 9; KEYNES, 1972, p. 17) ${ }^{8}$ como uma estimativa da capacidade máxima de pagamento que a Alemanha poderia suportar (ante um mínimo de 5 bilhões proposto anteriormente), a ser pago em 30 anos e sem juros, a partir de

Foram ainda reduzidas após 1921.

Ver, em especial, Keynes (1971b).

De fato, essas duas referências, datadas de 1919, são excertos da clássica obra de Keynes daquele ano, The economic consequences of the peace (KEYNES, 1971c), reimpressos posteriormente na coletânea Essays in persuasion, em 1931 (KEYNES, 1972). Há também outra referência subsequente que corresponde a um trecho de sua Revisão do Tratado (KEYNES, 1971d), de 1922. 
1923, perfazendo 50 milhões anuais aos quais deveriam ser adicionados créditos que a Alemanha possuía junto a seus aliados além de outras avaliações quanto aos territórios cedidos, aos navios mercantes, etc. no total de 500 milhões de libras.

Não só a carga direta que os pagamentos de reparações acarretariam, todavia, foi objeto da análise de Keynes (1971c), mas também o impacto, a ser sofrido pela Alemanha, que as concessões de territórios (e a estrutura industrial nestes instalada) aos Aliados poderia gerar, principalmente no que se refere à capacidade de produção de carvão e ferro. Ainda, o tópico das cláusulas impostas à taxação do comércio internacional (ou mesmo isenção, como no caso das exportações para a Alemanha a partir da região da Alsácia-Lorena, agora de domínio francês) foi analisado. Dado o arranjo geopolítico acordado, não foram poucas as perdas de matérias-primas e instalações sofridas pela Alemanha, como também não foram isolados os casos em que as fontes de insumos e as unidades de processamento dos mesmos foram cindidas, uma parte ficando com os Aliados e a parte complementar permanecendo com a Alemanha e vice-versa. Considerando o estado de ânimos prevalecente, a desorganização da produção em toda a Europa seria inevitável. Antes de chegar a uma cifra que correspondesse ao que considerava justo ser cobrado, cabe ressaltar que Keynes (1971c) nos apresenta um escrutínio, com ênfase nos casos da Bélgica, França e Grã-Bretanha, do que acreditava ser realmente devido pela Alemanha e seus aliados, somando o montante de 2.120 milhões de libras.

E foi nesse contexto que Keynes clamou pela moderação do acordo, exprimindo em tom profético sua visão acerca do desenrolar dos acontecimentos caso não fossem ouvidas suas preces, o que sucedeu, revelando válidas suas previsões a partir do desencadeamento da Segunda Guerra: "Se tencionamos deliberadamente o empobrecimento da Europa Central, a vingança, ouso prever, não hesitará" (KEYNES, 1972, p. 20). ${ }^{9}$

Diversas críticas a essa visão de mundo foram realizadas, sendo que uma argumentação mais extensa em favor da ideia de que a Alemanha poderia ter arcado com as reparações teve que esperar até o fim da Segunda Guerra, quando o francês Étienne Mantoux ${ }^{10}$ (1946) declara que a paz imposta à Alemanha não

$9 \quad$ Talvez aqui caiba reproduzirmos um trecho mais longo, do original, dada sua contundência: "If we take the view that for at least a generation to come Germany cannot be trusted with even a modicum of prosperity, that while all our recent Allies are angels of light, all our recent enemies, Germans, Austrians, Hungarians, and the rest, are children of the devil, that year by year Germany must be kept impoverished and her children starved and crippled, and that she must be ringed round by enemies; then we shall reject all the proposals of this chapter, and particularly those which may assist Germany to regain a part of her former material prosperity and find a means of livelihood for the industrial population of her towns. But if this view of nations and of their relation to one another is adopted by the democracies of Western Europe, and is financed by the United States, heaven help us all. If we aim deliberately at the impoverishment of Central Europe, vengeance, I dare predict, will not limp" (KEYNES, 1972, p. 20).

10 Filho do capitão Paul Mantoux (ver nota 2). Consultar também Abreu (2002: 12n) e, para uma análise mais detalhada, Harrod (1982, p. 275-279). 
era tão cartaginesa quanto sugerira Keynes e que, ademais, teria sido o sucesso da persuasão do mesmo responsável pelo abrandamento das reparações. A questão da carga de reparações ser suportável parece ter se tornado consensual entre estudiosos de história econômica, como nos relata Henig (1995, p. 63). A julgarmos por Aldcroft (1977), que se mostra bastante conservador acerca da capacidade de pagamento da Alemanha, encontramos o argumento de que se poderia ter feito um maior esforço de taxação e, consequentemente, o pagamento da carga integral pelas reparações imposta à Alemanha. Todavia, a que custo esse objetivo seria atingido? Ao custo da completa desgraça da Alemanha, ou de toda a Europa Continental? Sobre isso, não há dúvida quanto à resposta de Keynes:

A política de reduzir a Alemanha à servidão por uma geração, de degradar a vida de milhões de seres humanos, e de privar toda uma nação da felicidade deveria ser horrenda e detestável - horrenda e detestável, mesmo que fosse possível, mesmo que isso nos enriquecesse, mesmo que isso não disseminasse a ruína de toda a vida civilizada na Europa (KEYNES, 1972, p. 13, tradução nossa).

Seguindo imediatamente a publicação de As consequências econômicas da paz, todavia, não faltaram, como seria de se esperar, respostas críticas e acusações por parte de cidadãos de diversos países, tendo sido Keynes acusado inclusive de francofobia. Dentre as inúmeras cartas, artigos de jornal, etc., podemos encontrar uma ponderação de Keynes, dirigida aos franceses, de natureza bastante incisiva:

[...] no domínio das ações, há somente duas políticas possíveis - uma política de paz geral e uma política de desordem geral. A Europa tem se permitido rumar para uma posição onde grandes infortúnios podem ser inevitáveis. Mas estou convencido que o povo dessa nação [França] tem absolutamente resolvido em suas mentes que deseja a primeira política, e quaisquer incitamentos para o contrário, sob qualquer pretexto, são as mais simples leviandades (KEYNES, 1977, p. 157, tradução nossa).

Em suas propostas acerca do endividamento, cuja linha central pleiteava o cancelamento recíproco das dívidas entre os Aliados, Keynes (1972) apela ainda para a generosidade dos norte-americanos, pois, argumentava que mesmo que as dívidas fossem canceladas entre as nações europeias, uma carga insuportável continuaria a ser devida aos Estados Unidos. Fazendo uma caricatura da estrutura desse endividamento, Keynes (1972, p. 26, tradução nossa) afirma que "[...] a guerra terminou com todo o mundo devendo para todos os demais imensas somas de dinheiro. A Alemanha deve uma grande soma aos Aliados; os Aliados devem uma grande soma à Grã-Bretanha; e a Grã-Bretanha deve uma grande soma aos Estados Unidos". 
Tal apelo, entretanto, longe de ser cândido e passional, está sempre permeado de considerações sobre a estabilidade do sistema político prevalecente caso as dívidas fossem efetivamente cobradas: em primeiro lugar, Keynes duvida que pudessem ser pagas por mais que alguns poucos anos; e, em segundo lugar, argumenta que a imposição dessa carga geraria um sentimento de ódio potencialmente explosivo entre as nações. A generosidade necessária, disse Keynes (1972, p. 28), a ser atingida por uma política que promovesse imediatamente um clima amigável entre as nações, estaria em perfeita harmonia com os interesses dos benfeitores, leia-se, Grã-Bretanha e, principalmente, Estados Unidos.

Após apelar aos EUA por um alívio da carga de dívida, Keynes (1972, p. 28) sugere ainda um grande empréstimo internacional para a reconstrução da Europa, no qual "[...] a carga da obtenção dos recursos imediatos precisa inevitavelmente recair, em sua maior parte, sobre os Estados Unidos" (KEYNES, 1972, p. 28 , tradução nossa). Tecidas considerações sobre a insanidade dos governos europeus daquele então, a título de motivos para os Estados Unidos não efetuarem os empréstimos, Keynes, numa postura otimista, diz acreditar na substituição desses "falsos ídolos", sobreviventes da guerra que os criou, e faz uma súplica final em nome do progresso da humanidade, pedindo que os americanos se lembrem por um instante de que se trata da Europa, a qual, apesar de tudo, é "a mãe da arte e do conhecimento" (KEYNES, 1972, p. 30, tradução nossa).

Sobre a natureza desse esquema de empréstimo, discorre Keynes (1972, p. 30, tradução nossa):

Eu não me proponho a entrar em detalhes. Mas os contornos principais de todos os esquemas de um empréstimo internacional são praticamente iguais. As nações numa posição de prestar assistência, os neutros, o Reino Unido e, para a maior parte da soma requerida, os Estados Unidos, precisam prover créditos externos de compra para todas as nações beligerantes da Europa Continental, tanto para Aliados quanto para ex-inimigos.

A economia política de Keynes, a qual, apesar de estar em plena consonância com os interesses da Inglaterra de então, focaliza, acima de tudo, a capacidade de autodeterminação de uma nação (estando de acordo com Wilson nesse princípio básico), ainda mais importante naquele momento histórico em que o reerguimento da Alemanha, principal potência da Europa Continental e uma das maiores parceiras comerciais da Inglaterra pré-guerra (perdendo somente para a Índia em exportações e para os Estados Unidos em importações), significava o reerguimento de toda a Europa.

Vale ressaltar que, sob todos os aspectos, sobretudo econômicos, a Inglaterra continuava fora da Europa Continental (e continua), enquanto esta constituía um todo bastante interdependente (KEYNES, 1971c). Enquanto as condições econô- 
micas da Inglaterra não foram muito deterioradas, a Europa Continental passava por uma situação tão delicada que a falta de um arranjo adequado de cooperação poderia significar a ruína de todo esse bloco de países. Não custa repetir que o crescimento da Inglaterra seria bastante ameaçado por um acordo que não propiciasse à Alemanha - e à Europa Continental - os meios adequados ao seu reerguimento, como bem demonstra Keynes (1972) através da análise da intricada malha de inter-relações econômicas à escala internacional.

A autodeterminação das nações, enquanto princípio geral que acaba por nortear as opções de teoria e política ditas keynesianas, padece, entretanto, de mecanismos de coordenação quando da sua aplicação no âmbito internacional, como se tornou patente a partir desse evento histórico singular. Mazzucchelli (2009, p. 63-66) destaca claramente o papel que o "vazio de liderança" ${ }^{11}$ norte-americano desempenhou para o resultado final do acordo e para o que ocorreu nos anos seguintes: eram os Estados Unidos já os maiores credores internacionais dos Aliados e, talvez, os únicos politicamente aptos a pôr um fim no clima de revanchismo das negociações, que, por justificável que fosse em face das reais perdas humanas e de estrutura física sofridas pelos países Aliados, impunha uma carga insuportável e deletéria mesmo para o conjunto da Europa continental. Todavia, após a derrota de Wilson em Paris, os Estados Unidos não estavam dispostos a tratar dessas questões, reservando para si o direito à clausura em suas próprias questões internas, sendo que a recuperação dos créditos com os Aliados era o único contato desejado com o resto do mundo. Restava a todos os demais o retorno ao padrão ouro.

\section{Retorno ao Padrão Ouro}

Após divulgar suas considerações sobre o Tratado de Versalhes, e sobre suas possíveis revisões, Keynes publica o que muitos consideram ser o primeiro volume de uma trilogia voltada à teoria econômica, A tract on monetary reform, de 1923. Colocando essa obra em seu devido contexto, devemos ter em mente que, mais uma vez, e apesar da estratégia diversa utilizada, Keynes também visa influenciar as decisões de política econômica que porventura viessem a ser tomadas rumo à questão de honra britânica da época: o retorno ao padrão ouro e, mais do que isso, à paridade do pré-guerra com relação ao dólar, $\$ 4,86 / £$.

Por constituírem dois assuntos passíveis de separação - a) o retorno ao padrão ouro, significando uma mudança no padrão monetário; e b) o retorno a uma paridade específica, a do pré-guerra, significando uma apreciação da libra em relação ao patamar então vigente -, não haveria necessidade lógica de abordar-

$\overline{11}$ O argumento do "vazio de liderança" norte-americano é comumente identificado com o trabalho de Kindleberger (e.g. 1973, p. 297-299). 
mos os dois assuntos conjuntamente. Mas assim se deu o debate na ocasião, com Keynes se posicionando contra tal retorno conjunto entre 1922 e 1923. Antecipando algumas considerações efetuadas posteriormente, a escolha possível era entre o retorno ao padrão ouro com a manutenção da paridade vigente (sancionando a desvalorização da libra) e o retorno conjunto ao padrão e à paridade do pré-guerra, significando que a libra teria que se apreciar.

O retorno ao padrão ouro, longe de ser uma excentricidade britânica, constituía, para os dirigentes europeus, a tábua de salvação contra os males da inflação e da intensa volatilidade das taxas de câmbio no imediato pós-guerra. "A fé no poder do padrão ouro não era questionada. Este era a garantia [hallmark] de um retorno à 'normalidade'" (ALDCROFT, 1977, p. 126, tradução nossa). Todas as nações do velho mundo, e também os Estados Unidos, enfrentavam uma dose considerável de inflação, e alguns países como Alemanha, Áustria e Rússia já estavam passando por um processo de hiperinflação. A desorganização econômica da Europa parecia estar refletida nas paridades entre as moedas e também entre estas e o ouro. $\mathrm{O}$ retorno da libra para a paridade anterior à guerra não traduzia somente o anseio por estabilidade, mas a suposição de que, desse modo, a posição dominante da Inglaterra poderia ser restaurada.

Nos primeiros capítulos do Tract (KEYNES, 1971e), podemos observar uma análise cuidadosa e bem ao estilo da economia política clássica, na qual se explicitam as consequências das mudanças no valor da moeda (inflação e deflação) sobre classes funcionais selecionadas, a saber, rentistas, empresários e assalariados. ${ }^{12}$ Keynes procura deixar claro que a inflação seria, dos males, o menor, por prejudicar somente a classe inativa dos rentistas (devido à perda real sobre os rendimentos pré-estabelecidos), em oposição às consequências de uma deflação para a classe ativa dos empresários (e aqui se incluem os da área agrícola), que perderia nos contratos de empréstimos, no jogo especulativo dos estoques e nas próprias perspectivas de lucros. Também perderiam os assalariados, que ficariam, por conseguinte, sem seus empregos. ${ }^{13}$

\footnotetext{
12 "Keynes herdou da tradição clássica a ideia de que, para compreender como funcionam as economias capitalistas, é necessário levar em conta explicitamente os papéis desempenhados pelas principais categorias sociais / setores institucionais nessas economias" (SILVA; SANTOS, 2011, p. 111, tradução nossa).

13 Aqui deve estar claro que Keynes trata de inflações "administráveis", e não de hiperinflações como as vividas na época por Alemanha, Áustria ou Rússia (casos também analisados nessa obra). Keynes assume que o nível de organização dos trabalhadores é tal que lhes permita a defesa dos salários reais, coisa que uma hiperinflação ou um grau mais baixo de organização não poderia lograr, sendo, nesse contexto, a inflação também prejudicial aos trabalhadores. Para os empresários, a hipótese de uma inflação que ainda mantenha uma possibilidade razoável de se vislumbrar o horizonte para planejamento é também assumida por Keynes. Estão ausentes, ainda, arranjos de defesa por parte dos rentistas, como a correção monetária, a qual permite que essa classe não seja prejudicada pela inflação.
} 
A redistribuição de renda envolvendo o setor público é também abordada, primeiro sob a discussão da taxação implícita imposta pelo governo ao utilizar a inflação para se financiar, a qual, ressalta Keynes, tem sustentabilidade limitada. Posteriormente, sob o prisma da redistribuição, em favor do governo, que uma mudança de patamar (desvalorização) nos preços poderia causar, por implicar queda real das obrigações do governo para com os rentistas. Finalmente, chega à proposta de tributação sobre a propriedade (capital levy), ${ }^{14}$ a qual considera se constituir no mais racional dos métodos, apesar da dificuldade de aceitação pela opinião pública. Entretanto, enfrenta essa questão desmistificando tal "extorsão" da propriedade privada por parte do governo, a qual considera muito mais justa que a taxação via inflação, que não diferencia pequenos e grandes capitalistas. A questão se resume a quanto da renda nacional a sociedade considera aceitável que flua para a classe inativa, uma questão de distribuição (funcional) da renda típica da economia política clássica.

No terceiro capítulo dessa obra, que poderíamos considerar o capítulo teórico por excelência, Keynes parte para a explicação da Teoria Quantitativa da Moeda (TQM), ${ }^{15}$ a qual governaria o nível de preços no plano interno, julgando que a mesma, apesar de largamente mal interpretada, pode servir de guia para as relações entre quantidade de moeda e nível de preços somente no longo prazo, dada a grande variabilidade dos parâmetros relacionados aos hábitos e práticas correntes no curto prazo. Daí se segue seu famoso aforismo de que no longo prazo estaremos todos mortos, sendo o longo prazo um guia enganoso para os acontecimentos correntes (KEYNES, 1971e, p. 64-65). É na segunda parte desse capítulo, no qual Keynes tece considerações acerca da teoria da paridade do poder de compra, que podemos encontrar uma atitude de enfrentamento à política de retorno à paridade do pré-guerra. ${ }^{16}$

Deixando de lado contestações quanto ao estatuto teórico da paridade de poder de compra para a explicação dos movimentos das taxas de câmbio das moedas, o qual Keynes situa como essencialmente ricardiano, uma série de objeções à aplicabilidade direta dessa teoria é efetuada: "As taxas de câmbio efetivas são

$14 \quad$ Aliás, tal proposta já havia sido apresentada como pré-requisito para sanear a carga de dívida interna das nações beligerantes (KEYNES, 1972, p. 26) e, se foi posteriormente desacreditada por Keynes (1927, p. 206-207), o foi por razões de ordem prática, e não teóricas ou de julgamento, sobretudo por reconhecer a dificuldade de aplicação da mesma e as estreitas bases tributáveis de capital, as quais supunha anteriormente muito maiores em relação à renda nacional.

15 Keynes trata de uma interpretação para a TQM em que elementos expectacionais (portanto, subjetivos) relacionados ao comportamento (como o papel dos hábitos na conformação da demanda por moeda) estão presentes. Seria de se esperar, contudo, essa apresentação derivada da chamada versão de Cambridge para a TQM: Marshall e Pigou em detrimento de Fisher, como Keynes (1971e) deixa claro nesse terceiro capítulo.

16 É também no Tract que Kregel (1997) situa a formulação original da teoria da paridade descoberta das taxas de juros, a qual, segundo o mesmo, é tomada como base para a construção do capítulo 17 da Teoria Geral. 
frequentemente mais sensiveis e voláteis que as paridades do poder de compra, estando sujeitas à especulação, aos movimentos súbitos de capital, a influências sazonais, e a antecipações de mudanças iminentes na paridade do poder de compra" (KEYNES, 1971e, p. 72, grifo do autor, tradução nossa). ${ }^{17}$ Também o papel dos custos de transporte e das tarifas de importação (e a dificuldade de considerá-los inteiramente) é destacado, ressaltando ainda o caso dos bens e serviços que não entram no comércio internacional.

Aí começam suas considerações sobre a volta à normalidade pretendida pela Grã-Bretanha. De início, coloca sob suspeita o próprio equilíbrio dos fluxos internacionais de 1913, quando a paridade frente ao dólar era de $\$ 4,86$. E, mesmo que tomássemos esse ano como um marco de equilíbrio do comércio mundial, Keynes (1971e, p. 77) assevera que a teoria da paridade do poder de compra não estaria habilitada a nos fornecer os "verdadeiros" valores de troca, uma vez que desvios persistentes podem ocorrer quando se alteram as próprias relações entre os países. Para esse caso específico,

[...] o fortalecimento da posição financeira dos Estados Unidos frente à Europa, que resultou da guerra, pode ter alterado o velho equilíbrio numa direção favorável aos Estados Unidos. Nesses casos não é correto admitir que os coeficientes de paridade do poder de compra, calculados, como geralmente o são, por meio das variações dos números índices de poder de compra em geral com relação a seus níveis pré-guerra, devem se aproximar, no final das contas, das taxas de câmbio efetivas, ou que o poder de compra interno e o externo devem, no final das contas, guardar um com o outro a mesma relação que em 1913 (KEYNES, 1971e, p. 76, tradução nossa).

A instabilidade da moeda, passa a ressaltar Keynes (1971e) no capítulo subsequente, deve ser entendida em duas frentes: sua própria instabilidade com relação a um padrão de valor, normalmente o ouro; e a instabilidade desse padrão de valor em termos de poder de compra. Ao se levar em conta somente a primeira das instabilidades, deduz-se que a volta ao padrão ouro resolveria completamente o problema de instabilidade monetária, enquanto um outro problema é a flutuação do próprio ouro em termos de poder de compra. Se se ataca a primeira frente, sanciona-se, naquele dado momento, a desvalorização da libra; se, além da volta ao ouro, pretende-se restaurar a paridade do pré-guerra, é necessário que se incorra num processo de deflação.

Em conformidade com seus argumentos apresentados nos capítulos iniciais, resumidamente colocados acima, Keynes (1971e) assume a posição de que a de-

17 Sobre o papel da especulação, especificamente no que tange ao marco alemão, consultar Keynes (1978). 
flação (e, portanto, a volta à paridade anterior à guerra) não é desejável, por significar uma redistribuição em favor do rentista, da classe ativa para a inativa, i.e., do mutuário para o prestamista. ${ }^{18}$ A deflação teria ainda a capacidade de fazer com que a classe ativa postergasse seus gastos e transformasse, na medida do possível, ativos reais em dinheiro ou riqueza imediatamente disponível, uma vez que, se antecipada com grau suficiente de confiança, a deflação traria a expectativa de ganhos reais para os possuidores de moeda. ${ }^{19} \mathrm{E}$ mesmo que a deflação fosse desejável, não se segue que fosse possível, à exceção de moedas que porventura apresentassem pouca variação com relação a seus valores do pré-guerra. Isso porque a parcela da renda nacional transferida para os rentistas poderia ser grande demais para ser suportada pelos contribuintes. ${ }^{20}$

Uma outra ideia que parecia implícita à argumentação a favor do retorno ao padrão ouro era a de que este traria, simultaneamente, a estabilidade de preços e de câmbio, o que Keynes acreditava ser um erro baseado na extrapolação de condições históricas particulares em que os preços permaneceram relativamente estáveis em todo o mundo. Somente os dois se manteriam estáveis se os preços internos e externos se mantivessem, e o que estava realmente sendo mantida estável no pré-guerra era a taxa de câmbio, enquanto mudanças nos preços dos outros países poderiam afetar os preços internos. Para as condições vigentes no pós-guerra, Keynes argumenta que o padrão ouro poderia ser pouco eficaz, porquanto de reação muito lenta, dado que os preços em todos os países se encontravam fora de controle. Assim, um câmbio flutuante se adaptaria melhor para o objetivo de estabilidade de preços internos, a qual considerava preferível à estabilidade do câmbio, tecendo uma linha de argumentação a partir da grande quantidade de contratos fixados em moeda.

Ainda que o objetivo almejado fosse a estabilidade de câmbio e fosse decidido o retorno ao padrão ouro, Keynes adverte que tal estabilidade só poderia ocor-

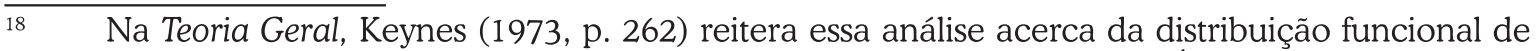
renda, avaliando seus impactos sobre a propensão marginal a consumir. É forçoso lembrar que já no segundo capítulo de As consequências econômicas da paz, descrevendo a "psicologia social" da Europa pré-guerra, Keynes (1971c) trata das diferentes propensões a consumir das classes e seus desdobramentos em termos de gastos e acumulação. O desenvolvimento dessas noções quanto à distribuição funcional de renda e os impactos da mesma nas variáveis de gasto erigiu as bases que o permitiram posteriormente advogar - e não profetizar, como leituras menos atentas tendem a caracterizar - pela eutanásia do rentista (KEYNES, 1973: 376). "Na controvérsia britânica acerca do padrão-ouro dos anos 1920, os interesses dos industriais claramente se colocaram como opostos aos interesses das finanças internacionais e do rentista na Inglaterra. Aqui, como sempre, Keynes se posicionou e advogou por um modo de ação que o colocavam na posição de um defensor do capital industrial e um crítico do capital financeiro" (DILLARD, 1946, p. 132, tradução nossa). Após a Teoria Geral, Keynes poderia ter descrito isso em uma sentença: ocorre um aumento da preferência pela liquidez.

20 Nos seus diversos artigos tratando do franco francês (que podem ser encontrados no volume XIX dos Collected Writings), Keynes enfatiza esse ponto de que, em última instância, a taxa de câmbio francesa seria determinada pela parcela da renda nacional que os contribuintes admitissem fluir para os rentistas, ponderando sobre os limites dessa transferência (e.g. KEYNES, 1972). 
rer com um retorno coordenado entre os países, e que, ainda assim, as condições favoráveis do século XIX, em que o progresso em outras áreas se fez acompanhar da exploração de novas minas, poderiam não se repetir. Considerar o sucesso prático do padrão ouro numa circunstância história específica, em detrimento de um padrão mais científico, consistia num grande erro para Keynes (1971e), ${ }^{21}$ que destaca também que o próprio ouro passara a constituir uma moeda "administrada" ${ }^{22}$ Mesmo que o padrão ouro voltasse a ser adotado, isso não significaria que o valor do ouro, em tempos de papel moeda e crédito bancário, viesse a ser determinado independentemente da política dos bancos centrais.

Ainda mais grave, percebe Keynes muitos anos antes da Conferência de Bretton Woods tornar o padrão ouro-dólar oficial, seria uma moeda "administrada" quase totalmente pelo Federal Reserve, visando os interesses internos de defesa do dólar contra a depreciação. Nessa situação, adverte os defensores desse regime sobre o quão longe do espírito de seu tempo estes se encontravam: longe dos interesses da estabilidade dos negócios, dos preços, e do emprego. "Em verdade, o padrão ouro já é uma relíquia bárbara” (KEYNES, 1971e, p. 138, tradução nossa).

Portanto, uma vez que considero a estabilidade de preços, crédito, e emprego de suprema importância, e desde que não sinto confiança de que um antiquado padrão ouro nos proporcionará mesmo o mínimo de estabilidade que costumava nos dar, eu rejeito a política de restauração do padrão ouro nas linhas do pré-guerra (KEYNES, 1971e, p. 140, tradução nossa).

O fato de que as reservas de ouro se encontravam mormente sob controle norte-americano, significando que a política monetária inglesa estaria sujeita aos humores do FED caso o padrão ouro fosse retomado, foi ainda objeto de uma das últimas considerações de Keynes (1981a) contra o esperado retorno: "Com nossas indústrias em sua condição presente agonizante e o emprego no nível atual, considero da primeira importância que nós devamos manter o controle de nosso sistema de crédito interno em nossas próprias mãos" (KEYNES, 1981a, p. 342, tradução nossa).

Com o retorno da Inglaterra ao padrão ouro, em abril de 1925, e mais essa batalha perdida, ${ }^{23}$ Keynes não desvia o foco do nível de emprego e utiliza todo o seu

${ }_{21} \quad$ Como destacado por Ferrari-Filho (2006, p. 215), o incômodo de Keynes com a utilização do padrão ouro em detrimento de um sistema monetário mais racional o acompanha desde seu primeiro livro, no qual a falta de elasticidade do sistema sob o padrão ouro é destacada (KEYNES, 1971a, p. 127; KEYNES, 1971a, p. 136).

22 Em The problem of the gold standard (KEYNES, 1981a), Keynes deixa ainda mais claro esse ponto de que o padrão ouro também é, de qualquer modo, um sistema "administrado", desfazendo a dicotomia automático / administrado, e explicitando que tal sistema plenamente automático e autorregulado não existia, na Inglaterra, pelo menos desde o século XVIII, e que talvez nunca tenha existido de fato.

23 Como ressalta Abreu (2002, p. 2), em texto que viria a prefaciar uma edição brasileira recente de As consequências econômicas da paz, "[...] de fato, uma possível forma de relatar a vida de Keynes é acompanhando as suas diversas derrotas pessoais que, em muitos casos, se converteriam em vitórias estratégicas". 
instrumental teórico exposto no Tract para refutar a política de Winston Churchill. Tal política, argumenta, no fundo visava provocar uma deflação. Como já havia deixado claro, o retorno ao padrão ouro e à antiga paridade correspondia à deflação (de preços e salários). Mas a "deflação não reduz os salários automaticamente. Os reduz causando desemprego" (KEYNES, 1972, p. 220, tradução nossa). Vale a pena remontar a exposição do raciocínio de Keynes para essa conclusão.

A expectativa de retorno ao padrão ouro por si só já desencadeou um movimento especulativo de antecipação que apressou o passo da libra rumo à antiga paridade, a qual, sendo estabelecida, significava uma apreciação da libra de 10\% e, portanto, uma redução dos ganhos dos setores exportadores na mesma proporção, num primeiro momento. Partindo desses setores, se iniciam as pressões para as reduções de custos, dos quais os salários constituem parcela significativa, e como não há mecanismo que assegure uma redução simultânea de preços e salários em todas as categorias, dá-se início a uma espiral deflacionária na qual o conflito distributivo trata de fazer com que as categorias mais fortes se aproveitem do momento de redução para ganharem com relação às mais frágeis. A transferência de riqueza a favor dos rentistas causada pela deflação, que não tem como proceder de forma coordenada e instantânea, faz com que essa espiral seja também de depressão e desemprego, novamente a começar pelos setores exportadores, a qual só cessa quando o desemprego atinge um nível suficiente para os salários se adequarem ao novo patamar. ${ }^{24} \mathrm{~A}$ política monetária, agindo sobre o canal do crédito, também pode ser - e via de regra é - usada deliberadamente para atingir esse objetivo.

Do ponto de vista do balanço de pagamentos, a queda das exportações e aumento das importações, resultante do câmbio apreciado, tinha que ser compensada por uma taxa de juros interna maior com a finalidade de atrair capitais (e o foi à época, com os juros em Londres estando consistentemente acima dos praticados em Nova Iorque). No entanto, os juros altos também cumpriam o papel deliberado de acelerar a depressão e reduzir os salários via desemprego, a partir da restrição do crédito causada pela política de dear money.

Nos remetendo também ao tópico anterior, podemos ir ao encontro da interpretação de Dillard (1946, p. 127, tradução nossa):

Por volta de 1930 Keynes viu suas previsões dos anos 1920 concernentes às dívidas de guerra se verificarem. As vastas transferências internacionais advindas das

\footnotetext{
$\overline{24}$ Talvez seja ilustrativo atentar para a contundente descrição oferecida por Keynes (1972, p. 223) utilizando o exemplo dos mineradores de carvão, vítimas do economic juggernaut, os quais foram representativos do sacrifício necessário à volta aos $\$ 4,86$, sentindo na pele os fundamental adjustments impostos pelo tesouro e pelo banco central britânicos para satisfazer a impaciência da City. O raciocínio descrito poderia ser interpretado, modernamente, em termos de uma rigidez à baixa dos salários nominais acrescida de problemas de coordenação.
} 
dívidas de guerra, em conjunção com o padrão ouro internacional (após 1925), foram responsáveis pelo fracasso das taxas de juros na Inglaterra serem reduzidas a um nível compatível com o pleno emprego, de acordo com Keynes. [...] A elevada taxa de juros de mercado levou a um volume inadequado de investimento, que, por seu turno, foi o fator principal para levar a indústria britânica à depressão no período em que a maior parte dos grandes países capitalistas estava desfrutando de um grau considerável de prosperidade..$^{25}$

Nesse particular, mas não somente associada ao retorno ao padrão ouro por parte da Inglaterra, cujo agravante foi a obstinação pela paridade pré-guerra, a argumentação perseguida por Eichengreen (1992) vai no sentido de conectar as "amarras douradas" ao desempenho econômico mundial dos anos 1920 e à Grande Depressão. As restrições impostas pelo padrão ouro são encaradas como representativas de uma condução de política econômica mais conservadora, da qual a simples saída do padrão ouro não constitui condição suficiente de libertação, mas a possibilidade de políticas mais ativas. Todavia, o papel de contágio que a utilização desse regime em escala mundial pode desempenhar se constitui num ponto basilar do seu argumento, destacando que a crise originada nos Estados Unidos em fins de 1929 se refletiu com a velocidade e magnitude observadas nos outros países por conta da correia de transmissão inerente ao padrão ouro.

\section{A Grande Depressão}

Por ser esse tópico comumente associado à teoria de Keynes, gerando frequentemente estereótipos deste autor como o salvador do capitalismo ou o defensor inveterado de gastos públicos de qualquer natureza, entendemos como inevitáveis algumas observações de cunho mais teórico; é importante reter a descrição genérica de uma crise oferecida na Teoria Geral (KEYNES, 1973, p. 313-320), no intuito de atentarmos para a sequência de eventos observada na Grande Depressão, à qual retornaremos abaixo sob outra ótica. Inicialmente, ocorre um colapso na eficiência marginal do capital, ou seja, a visão dos empresários com relação a seus lucros prospectivos se torna pessimista. Seguem-se um aumento na preferência pela liquidez e uma diminuição na propensão marginal a consumir, o que faz com que a situação se agrave fortemente. Em última instância, se interpretarmos a teoria da preferência pela liquidez como uma teoria da escolha e precificação de

\footnotetext{
$25 \quad$ "Parecia que os eventos tinham justificado os prognósticos de Keynes de 1925. Ele previu greves e greves aconteceram; ele disse que o padrão ouro era impraticável e assim se provou ser; ele disse que a indústria sofreria sob o padrão ouro e sofreu. Em 1931 encontramos Keynes pesarosamente descrevendo a si mesmo como uma Cassandra cujas previsões eram proféticas mas a cujas profecias nunca se dava atenção" (DILLARD, 1946, p. 136, tradução nossa).
} 
ativos em geral, inclusive ativos "reais", é a elevação da preferência pela liquidez que deflagra um processo de crise.

Decerto que a Grande Depressão não foi uma crise qualquer, e que uma conjunção de fatores operou para uma elevação colossal e abrupta da preferência pela liquidez, que se revelou, ademais, sustentada. A elevação da preferência pela liquidez, entretanto, não pode ser reduzida a medidas unidimensionais, tais como o aumento no montante de moeda entesourado ou a elevação da taxa de juros, mas se trata da movimentação de uma enorme variedade de ativos em direção a posições mais líquidas e de toda sorte de repercussão na precificação dos mesmos engendrada por essa mudança (ou pela mera tentativa de mudança). Uma coisa permanece a partir dessa explicação: "O nervo da questão foi a interação perversa que se estabeleceu entre o colapso das expectativas, a contração do crédito e a deflação de preços" (MAZZUCCHELLI, 2009, p. 213).

Não podemos nos omitir, ademais, de realçar a situação particular da Inglaterra, que passou por uma recessão já na virada para os anos 1920 e pela deflação ocasionada pelo retorno ao padrão ouro em meados dessa década, tendo experimentado, em resumo, por praticamente todo o decênio, um incômodo convívio com mais de um milhão de desempregados no país. Ao voltarmos nosso foco para a Grande Depressão, discorrendo sobre a natureza do problema podemos encontrar a assertiva de Keynes (1972, p. 336, tradução nossa) de que "[...] este é, no sentido mais estrito, um problema econômico ou, para exprimir melhor, sugerindo uma combinação de teoria econômica com a arte da política, um problema de economia política". Em maio de 1929, às vésperas do marco da Grande Depressão (agosto para a produção industrial nos Estados Unidos e outubro para o crack da bolsa de Nova Iorque), Keynes, nessa ocasião em coautoria com Hubert Henderson, publica um panfleto em defesa dos compromissos de campanha de Lloyd George, apoiando seu programa de obras públicas e considerando que mesmo que este não conseguisse atingir o número de empregos planejado, já recolocaria a Inglaterra na direção correta. Discorda, portanto, veementemente, da "[...] crença conservadora de que há alguma lei da natureza que impede os homens de estarem empregados, de que é 'imprudente' empregar os homens, e de que é financeiramente 'sadio' manter um décimo da população em inatividade por um período indefinido" (KEYNES, 1972, p. 90-91, tradução nossa) ${ }^{26}$ Em contraposição, resumindo a plataforma defendida por Lloyd George, a qual estava então em consonância com sua visão de mundo, explica que:

$26 \quad$ Culpa, inclusive, a política econômica de Churchill pelo quadro insatisfatório do emprego, através dos exemplos do desempenho recente na construção de casas e de estradas (KEYNES, 1972, p. 102). 
[...] lidar com o desemprego por meio de uma política vigorosa de desenvolvimento nacional objetiva, por um lado, prover trabalho imediato para um grande número de homens, e, por outro lado, retirar os negócios e a indústria do poço em que tinham caído e recolocá-los na rodovia do progresso ao longo da qual deveriam então estar aptos a seguir adiante por sua própria conta (KEYNES, 1972, p. 94, tradução nossa).

Quando das considerações acerca do volume de emprego que poderia ser gerado a partir dos programas de obras públicas, Keynes (1972, p. 102) deixa claro que devem ser levados em conta os empregos indiretos gerados a partir de um gasto inicial, por exemplo, na construção de estradas.

Não há nada fantasioso ou inconsistente sobre a proposição de que a construção de estradas requer uma demanda por materiais para estradas, que requer uma demanda por trabalho e também por outras mercadorias, o que, por seu turno, requer uma demanda por trabalho. Essas reações são da própria essência do processo industrial (KEYNES, 1972, p. 105, tradução nossa).

A essa altura, estamos tratando das complementaridades entre as cadeias produtivas - tão bem compreendidas e esmiuçadas por Piero Sraffa, ${ }^{27}$ de um lado, e Wassily Leontief, de outro -, de um multiplicador da produção do ponto de vista dos impactos gerados no emprego, os quais Keynes (1972, p. 106, tradução nossa) julga constituírem o $\mathrm{ABC}$ da economia: "De um modo geral, o emprego indireto que esquemas de gastos em capital requereria é muito maior que o emprego direto".

Mas isso não é o total da estória. Adicionalmente ao emprego indireto de que estamos tratando, uma política de desenvolvimento promoveria o emprego de outras maneiras. $\mathrm{O}$ fato de que um grande número de trabalhadores que agora estão desempregados estaria recebendo salários ao invés de seguro-desemprego significaria um aumento no poder de compra efetivo que daria um estímulo geral ao comércio (KEYNES, 1972, p. 106, tradução nossa).

O multiplicador total do emprego, exposto posteriormente por Richard Kahn ${ }^{28}$ (1931), leva em conta, em seus termos, tanto o emprego "primário" - este incluindo as parcelas de emprego direto e indireto envolvidas -, quanto o emprego "secundário",

$27 \quad$ Digna de nota é a observação de que Keynes já havia tido acesso, em 1928, aos esboços da obra de Sraffa, publicada mais de 30 anos depois, como nos relata o autor no prefácio de Produção de mercadorias por meio de mercadorias (SRAFFA, 1973, p. vi).

28 O próprio Richard Kahn (1984, p. 91) considera o panfleto Can Lloyd George do it?, escrito por Keynes em coautoria com Hubert Henderson em 1929 (KEYNES, 1972), como o marco que o levou a escrever seu artigo em que expõe o multiplicador do emprego (KAHN, 1931). 
que resulta do aumento da produção nas indústrias de bens de consumo, necessário para suprir a demanda ampliada a partir do aumento de salários e lucros. Retornando a Keynes (1973, p. 113-131), isso se converteria, anos depois, em seu multiplicador de renda, a partir de uma aproximação direta entre emprego e renda, no qual o gasto em investimento corresponde, de um ponto de vista teórico, ao gasto "primário", i.e., gastos diretos e indiretos incidentes na cadeia produtiva. Os gastos em consumo, esses de natureza passiva, deveriam ser tomados como "secundários".

Não estamos sugerindo, e isso fugiria do escopo deste trabalho, que estariam presentes nesse panfleto todos os elementos constitutivos da Teoria Geral, mas a intuição acerca do multiplicador, e do princípio da demanda efetiva, parece clara. Ademais, sua análise flui em termos do (ainda vindouro à época) Tratado sobre a moeda (KEYNES, 1971f). Vale notar, enfatizando os desequilíbrios entre investimento e poupança: "Quando o investimento segue à frente da poupança nós temos um boom, intenso emprego, e uma tendência à inflação. Quando o investimento segue atrás, nós temos um colapso e desemprego anormal, como no presente" (KEYNES, 1972, p. 117, tradução nossa).

Já diante de "[...] uma das maiores catástrofes econômicas da história moderna” (KEYNES, 1972, p. 126, tradução nossa), como descreve a Grande Depressão, Keynes sugere uma explicação a partir da seguinte sequência: os trabalhadores estão desempregados porque os industriais não esperam ter lucros com um volume de produção que os empregaria, isso porque os preços têm caído proporcionalmente mais que os custos, uma vez que a produção passada não está sendo vendida: a proporção da renda gasta em consumo está menor que a proporção dos custos de bens de consumo vis-à-vis de bens de capital; ${ }^{29}$ os produtores de bens de consumo têm prejuízos porque a poupança é muito elevada. Solução: mais gastos em consumo ou em investimento (bens de capital). Já o problema com os gastos (insuficientes) em bens de capital decorre de uma decisão acerca da alocação da riqueza, entre ativos mais líquidos e investimento em bens de capital; ${ }^{30}$ como nas crises ocorre uma corrida para a liquidez, os preços dos bens de capital também despencam, acarretando perdas para quem os produz. ${ }^{31}$ Como a produção de

\footnotetext{
$29 \quad$ Vale notar que é em termos da comparação dessas duas proporções que Keynes (1937, p. 220) remonta sua explicação sobre o multiplicador em seu conhecido artigo em defesa da Teoria Geral.

30 Essa segunda decisão representa claramente a preferência pela liquidez dos possuidores de riqueza, cujo experimento conceitual de Keynes no Tratado visa retratar, contrapondo entesouramento e investimento (KEYNES, 1971f, p. 127). Esses dois conjuntos distintos de decisões, um na esfera da renda entre consumo e poupança, e outro na esfera da riqueza entre entesouramento e investimento, também estão presentes na Teoria Geral (KEYNES, 1973, p. 166) e originam, ainda no Tratado, a chamada teoria dos dois preços: um para os bens de consumo / produto corrente e outro para os bens de investimento / ativos de capital.

31 Nessa sequência, podemos identificar a tríade colapso da eficiência marginal do capital/aumento da preferência pela liquidez/diminuição da propensão a consumir, explicitada na Teoria Geral, a qual nos referimos no início dessa seção.
} 
bens de capital é bastante dependente de empréstimos, Keynes julga fundamental reativar esse circuito de crédito específico, clamando pela atividade coordenada dos bancos centrais de Estados Unidos, Inglaterra e França para "[...] restaurar a confiança ao mercado internacional de empréstimos de longo-termo" (KEYNES, 1972, p. 134, tradução nossa).

Num ulterior artigo de opinião, Keynes (1982, p. 126, tradução nossa) reforça alguns pontos sobre o que veio a se tornar conhecido como princípio da demanda efetiva: "É frequentemente dito pelos sabichões que nós não podemos gastar mais do que ganhamos. Isto é, naturalmente, bem verdade para o indivíduo, mas muitíssimo enganoso se aplicado à comunidade como um todo", caso em que "[...] seria muito mais verdade dizer que nós não podemos ganhar mais do que gastamos". Assim, conclama a opinião pública a "[...] considerar nosso dever cívico estimular e promover todas as formas sensatas de gasto" (KEYNES, 1982, p. 127, tradução nossa). No quadro de uma economia profundamente deprimida, apesar de ponderar também as diversas possibilidades de intervenção visando a retomada dos gastos privados, se fazia forçoso reconhecer que era "[...] da maior importância que as autoridades públicas pudessem restabelecer seus programas de gastos de capital sobre todos os propósitos úteis tão logo quanto possível, e numa escala tão grande quanto possível" (KEYNES, 1982, p. 126, tradução nossa).

Retomando a discussão sobre o impacto de um gasto inicial no volume total de emprego gerado ${ }^{32}$ e, após a publicação do referido artigo de Kahn (1931), já utilizando a denominação de multiplicador, Keynes (1972) qualifica a natureza dessas repercussões condenando o exagero nas estimativas das mesmas e enumerando os fatores que impedem que os impactos decorrentes do gasto inicial se propaguem indefinidamente, como se fossem restritos somente às defasagens entre recebimentos e gastos:

A cada estágio uma determinada proporção da renda ampliada não é passada adiante em emprego ampliado. Alguma parte será poupada pelo recebedor; alguma parte eleva os preços e assim diminui o consumo em outra parte, exceto na medida em que os produtores gastem seus lucros ampliados; alguma parte será gasta em importações; alguma parte é meramente uma substituição de gastos previamente efetuados a partir de transferências governamentais ${ }^{33}$ ou caridade particular ou poupanças pessoais; e alguma parte pode chegar ao Tesouro sem aliviar o contribuinte em proporção equivalente (KEYNES, 1972, p. 340, tradução nossa).

\footnotetext{
$32 \quad$ Numa série de artigos posteriormente reunidos num panfleto denominado The means to prosperity, de 1933, que foi acrescido aos Essays in Persuasion, apesar de não constarem da coletânea original.

The dole, no original, que se refere a programas nos moldes do seguro-desemprego.
} 
Desse modo, para além de sua consagrada "lei psicológica fundamental" (KEYNES, 1973, p. 96, tradução nossa), segundo a qual os "[...] homens estão dispostos, via de regra e na média, a aumentar seu consumo quando sua renda se eleva, mas não tanto quanto a elevação de sua renda[...]", Keynes explicita toda sorte de "vazamentos" que fazem com que um aumento no gasto inicial não seja propagado ad infinitum..$^{34} E$ importante enfatizar que Keynes (1972, p. 342) estava interessado em duas proporções: a) entre gastos iniciais e renda, no intuito de verificar se não havia vazamentos também nesses gastos (autônomos à renda, como deixou claro na Teoria Geral), seja para o exterior, seja para movimentar riqueza velha, noutros termos, se o gasto inicial ao se propagar ao longo da cadeia estava sendo refletido inteiramente em emprego "primário" no país; e b) entre a renda recebida e a efetivamente gasta, ou seja, quanto da renda no emprego "primário" se transformava em gasto gerador de emprego "secundário". "Para obter o multiplicador nós simplesmente temos que estimar essas duas proporções" (KEYNES, 1972, p. 342, tradução nossa).

Ao tratar de aspectos práticos da implantação de uma política de gastos públicos, Keynes (1972, p. 356) destaca a necessidade de coordenação entre os países a fim de evitar pressões desestabilizadoras na balança comercial, uma vez que "vazamentos" em alguma etapa para a compra de bens produzidos em outros países seriam inevitáveis, e se um país deflagrasse sozinho um processo de crescimento induzido pelos gastos públicos, arcaria de imediato com as consequências de um aumento das importações.

Movendo-nos um pouco do terreno específico das políticas de gastos, vale notar que é ainda nos termos dos desequilíbrios investimento / poupança que Keynes (1981b) desenvolve um eloquente argumento em carta dirigida a Montagu Norman, presidente do Banco da Inglaterra à época. Propõe que as saídas para a recessão necessariamente passariam pelo aumento do saldo comercial e do investimento doméstico. No primeiro caso, políticas de restrições quantitativas e tarifárias ${ }^{35}$ são propostas, e, para o aumento do investimento, sugere o aprofun-

$34 \quad$ Vale ressaltar que nesse então, e ao contrário do que podemos encontrar na Teoria Geral, Keynes está concentrado no multiplicador do emprego, mas já faz uma menção ao multiplicador da renda (KEYNES, 1972, p. 346n). O foco nos "vazamentos" é fundamental também na análise de Kahn (1931), o qual considera que o ponto mais difícil de ser explicado acerca do multiplicador não é a lógica da propagação dos gastos, mas justamente porque esses não se propagam indefinidamente (KAHN, 1984).

35 Nesse mesmo ano, Keynes avança um argumento explicitamente protecionista perante o Macmillan Comittee (testemunhos presentes no volume XX dos Collected Writings, e debate sumarizado por Harrod, 1982, p. 424-431), que veio a expor para o grande público numa série de artigos no ano seguinte, reunidos em um capítulo do Essays (KEYNES, 1972) denominado Mitigation by tariff. Mantendo o foco no desemprego, Keynes (1972) defende um imposto de importação, não acreditando mesmo que um orçamento prudente pudesse ser estabelecido sem tal recurso, ainda que como uma medida temporária. Isso porque os déficits ingleses na balança comercial poderiam ainda ser ampliados se fossem tomadas medidas expansionistas internamente, estando a libra sobrevalorizada após o retorno à paridade do pré-guerra. Nesse caso, Keynes argumenta que 
damento da política de cheap money já em curso. Tal aprofundamento deveria ser feito através de uma política coordenada entre Londres, Nova Iorque e Paris, uma vez que movimentos em bloco não implicariam perda de reservas em ouro para nenhuma das partes. Como acredita ainda que o problema do investimento estaria relacionado à taxa de juros de longo prazo, que considerava anormalmente elevada, advoga pela atuação efetiva do Banco da Inglaterra no espectro dos títulos de longo prazo, trocando-os pelos de curto prazo, ou seja, comprando papéis de longo prazo e vendendo de curto prazo.

A problemática relativa à taxa de juros de longo prazo seria retomada algum tempo depois num pequeno artigo para The Economic Journal (KEYNES, 1932), em que se repete a sugestão de emitir papéis de curto prazo para trocá-los pelos de longo, a fim de reduzir a taxa de longo prazo, medida que Keynes julga mais efetiva naquele dado momento que a política de cheap short-term money, apesar de não se colocar em questão a necessidade de manutenção desta última. Todo o debate envolvia a conversão da dívida de guerra, de longo prazo, para a qual um esquema adequado de permuta era premente. Tal esquema, apesar de acarretar um alívio da carga total de dívida, mostraria seu caráter de essencialidade a partir dos efeitos na taxa de juros de longo prazo e na consequente recuperação dos negócios. Assim Keynes (1932, p. 415, tradução nossa) abre esse artigo: "Uma redução da taxa de juros de longo prazo para um nível baixo é provavelmente a mais necessária de todas as medidas se quisermos escapar da depressão e assegurar uma revitalização duradoura do empreendimento".

\section{Notas sobre o Conceito de Economia Política e Considerações Finais}

Ao longo deste trabalho, algumas referências ao termo economia política foram efetuadas: a) ainda na segunda seção, ligamos a economia política de Keynes à capacidade de autodeterminação de uma nação (sem ignorarmos os interesses da Inglaterra de então); b) na terceira seção, nos referimos à análise efetuada no Tract como proveniente de um estilo característico da economia política clássica; e c) na quarta seção, a ligação da teoria econômica à arte da política foi ilustrada pela tentativa de resolução dos problemas práticos advindos da Grande Depressão.

os empregos, que poderiam ser oferecidos na Inglaterra, estavam sendo drenados para outros países com custos de mão de obra inferiores em termos monetários. Com o abandono do padrão ouro e a consequente desvalorização da libra, em setembro de 1931, Keynes imediatamente revê sua posição, passando a desaconselhar medidas protecionistas. Todavia, como podemos observar num adendo ao Macmillan Report feito por Keynes (1981b, p. 297-299), seu argumento central, mesmo desconsiderando-se a situação da balança comercial, gira em torno do emprego que poderia ser induzido internamente por um aumento das exportações e diminuição das importações, num contexto tal que o argumento a favor do livre-comércio seria mesmo equivocado por estar baseado num suposto equilíbrio de pleno emprego. 
Assim, dada a inevitável controvérsia acerca da utilização do termo economia política e o que este efetivamente pretende designar, principalmente quando associado a um autor confessamente inserido na "burguesia instruída" e politicamente liberal, ${ }^{36}$ julgamos necessárias algumas observações. É fundamental que diferenciemos pelo menos dois aspectos: a economia política como relacionada ao método de análise da escola clássica, identificada com a temática da produção e distribuição, e a economia política como política econômica, mais ligada às decisões de natureza prática concernentes à esfera econômica. Entendemos aqui que Keynes se encaixa em ambos os aspectos do termo. Devemos, então, recorrer a Teixeira (2000, p. 85), que explicita, logo de saída, a indissociabilidade entre o significado original do termo economia política - como relacionado ao estudo da produção, acumulação, circulação e distribuição de riquezas - e as proposições de natureza prática a este associadas.

Adam Smith (1996, p. 413), ao considerar que um dos objetivos da economia política é o de "[...] prover uma renda ou manutenção farta para a população ou, mais adequadamente, dar-lhe a possibilidade de conseguir ela mesma tal renda ou manutenção[...]", ${ }^{37}$ subsidia completamente a inclusão desses escritos de Keynes em tal categoria. Em obra realçando os objetivos da economia política, ${ }^{38}$ escreve John Neville Keynes (1999, p. 20, tradução nossa): "No concernente ao escopo da economia política, nenhuma questão é mais importante, ou de certa forma mais difícil, que sua verdadeira relação com os problemas práticos". Este tece ainda uma série de observações acerca da dificuldade de separarmos os ramos positivo e normativo da economia, e também de diferenciarmos esses ramos da arte da economia política, ou seja, do conjunto de meios para atingirmos determinado objetivo tido como socialmente desejável. "O objeto de uma ciência positiva é o estabelecimento de uniformidades, de uma ciência normativa a determinação dos ideais, e de uma arte a formulação de prescrições" (KEYNES, 1999, p. 22, grifo do

"O maior propósito de Keynes pode ser caracterizado como uma tentativa de apoiar o liberalismo político com um novo programa econômico e fortalecer esse programa econômico com uma nova economia política. Nesse sentido, Keynes segue na tradição dos grandes economistas britânicos desde Adam Smith, todos os quais eram liberais, com a possível exceção de Malthus" (DILLARD, 1946, p. 145, tradução nossa). Todavia, a "[...] importância histórica da nova economia política de Keynes é que esta fornece as bases teóricas para um novo liberalismo, o qual, ao contrário do liberalismo clássico, rejeita o laissez faire" (DILLARD, 1946, p. 151, tradução nossa).

37 Teixeira (2000, p. 94), ao elucidar uma passagem de Smith do qual o trecho citado faz parte, reafirma o objetivo dos economistas políticos clássicos como situado na discussão e formulação de políticas concretas. Dada a semelhança de caráter, comparar essa passagem de Adam Smith à citação anterior de Keynes (1972, p. 94), acima.

38 Neville Keynes (1999, p. 7) utiliza o termo political economy no seu significado original (clássico), relacionado ao fenômeno da riqueza, porém o iguala a economics, equiparação também efetuada por Alfred Marshall no mesmo ano com o adendo do foco no indivíduo: "Assim, de um lado é um estudo da riqueza; e do outro, e mais importante, uma parte do estudo do homem." (MARSHALL, 1996, p. 77). Ambas as publicações datam de 1890. 
autor, tradução nossa), resume. Após destacar a possibilidade, e mesmo a necessidade, de separarmos o ramo positivo da economia política, o autor afirma que a estrita separação é, no final das contas, indesejável, nas bases de que a economia positiva deve constituir uma etapa prévia à sua aplicação, mas não é um fim em si mesma, devendo ser usada para embasar as aplicações de ordem prática, em que considerações éticas devem adquirir seu devido peso (KEYNES, 1999, p. 26).

Retomando o ponto de vista de Keynes (sobretudo, mas não somente, o do Tract) como um economista político profundamente arraigado ao método clássico de pensamento, torna-se inevitável nos remetermos a Pasinetti (1974, p. 42-43, tradução nossa), de acordo com o qual a concepção de Keynes do sistema econômico (referindo-se ao descrito na Teoria Geral) é tipicamente clássica:

O uso de variáveis macroeconômicas, a divisão de todos os agentes econômicos em grandes categorias (consumidores e empresários no caso de Keynes), a busca pela determinação da taxa de juros - e, por conseguinte, da distribuição de renda - numa esfera fora daquela do produto - todas essas são características herdadas da análise econômica clássica.

A economia política de Keynes, como se sabe, não se inicia com o Tratado de Versalhes, tampouco termina com a Grande Depressão. Nem mesmo podemos reduzir sua contribuição à esfera econômica - seja economics ou political economy - como atestam seus primeiros escritos anteriores a Versalhes em filosofia e lógica, sua efetiva participação pós-depressão para os esforços de guerra, ou, ainda, após a Segunda Guerra, na Conferência de Bretton Woods. ${ }^{39} \mathrm{O}$ período aqui tomado, todavia, já nos parece suficiente para defendermos o ponto de que Keynes, a exemplo de seus precursores clássicos em matéria de economia política, não só se envolveu, na prática, em assuntos dessa natureza, mas também justificou teoricamente suas posições, como a Teoria Geral é evidência inconteste. Deve estar claro, contudo, que sua magnum opus ultrapassa em muito tal natureza de justificação, como atestam, por exemplo, suas teorias da preferência pela liquidez, ou do investimento baseado na eficiência marginal do capital, ou, ainda, da determinação da renda agregada via multiplicador, as quais se unem numa teoria da escolha e precificação de ativos em geral, demonstrando os entraves que os resultados dessa escolha e precificação de ativos podem resultar do ponto de vista da renda, que estão muito além de uma racionalização para os gastos públicos, como muitos tentam fazer parecer que se resume a teoria de Keynes.

$39 \quad$ Neste sentido, "[...] encaixa-se naquela categoria antiquada, difícil de definir, de economista político, alguém que vê a economia como um ramo do ofício de estadista em vez de uma disciplina fechada, com leis invariáveis" (SKIDELSKY, 1999, p. 21). 


\section{Referências}

ABREU, M. P. Keynes e as consequências econômicas da paz. Rio de Janeiro: DE/PUCRJ, 2002. (Texto para Discussão, 454).

ALDCROFT, D. H. From Versailles to Wall Street: 1919-1929. Berkeley: University of California Press, 1977.

DILLARD, D. The pragmatic basis of Keynes's political economy. The Journal of Economic History, v. 6, n. 2, p. 121-152, 1946.

EICHENGREEN, B. Golden fetters: the gold standard and the great depression, 1919-1939. New York: Oxford University Press, 1992.

FERRARI-FILHO, F. As concepções teórico-analíticas e as proposições de política econômica de Keynes. Revista de Economia Contemporânea, v. 10, n. 2, p. 213-236, 2006.

FITZGIBBONS, A. Keynes's vision: a new political economy. Oxford: Clarendon, 1990.

HARROD, R. F. The life of John Maynard Keynes. New York: W. W. Norton EJ Company, 1982.

HENIG, R. Versailles and after: 1919-1933, 2nd ed. London: Routledge, 1995.

KAHN, R. F. The relation of home investment to unemployment. The Economic Journal, v. 41, n. 162, p. 173-198, 1931.

The making of Keynes' General Theory. Cambridge: Cambridge University Press, 1984.

KEYNES, J. M. The Colwyn Report on national debt and taxation. The Economic Journal, v. 37, n. 146, p. 198-212, 1927.

A note on the long-term rate of interest in relation to the conversion scheme. The Economic Journal, v. 42, n. 167, p. 415-423, 1932.

The general theory of employment. The Quarterly Journal of Economics, v. 51, n. 2, p. 209-223, 1937.

Indian currency and finance. Cambridge: Macmillan, 1971a. (The collected writings of John Maynard Keynes, v. I).

Activities 1914-1919: the Treasury and Versailles. Cambridge: Macmillan, 1971b. (The collected writings of John Maynard Keynes, v.XVI).

The economic consequences of the peace. Cambridge: Macmillan, 1971c. (The collected writings of John Maynard Keynes, v. II).

A revision of the Treaty being a sequel to the economic consequences of the peace. Cambridge: Macmillan, 1971d. (The collected writings of John Maynard Keynes, v. III).

A tract on monetary reform. Cambridge: Macmillan, 1971e. (The collected writings of John Maynard Keynes, v. IV).

A treatise on money. U.1: the pure theory of money. Cambridge: Macmillan, 1971f. (The collected writings of John Maynard Keynes, v. V).

Essays in persuasion. Cambridge: Macmillan, 1972. (The collected writings of John Maynard Keynes, v. IX).

. The general theory of employment, interest, and money. Cambridge: Macmillan, 1973. (The collected writings of John Maynard Keynes, v. VII). 
Activities 1920-1922: treaty revision and reconstruction. Cambridge: Macmillan, 1977. (The collected writings of John Maynard Keynes, v. XVII).

Activities 1922-1932: the end of reparations. Cambridge: Macmillan, 1978. (The collected writings of John Maynard Keynes, v. XVIII).

. Activities 1922-1929: the return to gold and industrial policy. Cambridge: Macmillan, 1981a. (The collected writings of John Maynard Keynes, v. XIX).

. Activities 1929-1931: rethinking employment and unemployment policies. Cambridge: Macmillan, 1981b. (The collected writings of John Maynard Keynes, v. XX).

Activities 1931-1939: world crises and policies in Britain and America. Cambridge: Macmillan, 1982. (The collected writings of John Maynard Keynes, v. XXI).

Economic articles and correspondence: academic. Cambridge: Macmillan, 1983. (The collected writings of John Maynard Keynes, v. XI).

KEYNES, J. N. The scope and method of political economy. Kitchener: Batoche Books, 1999.

KINDLEBERGER, C. P. The world in depression: 1929-1939. Berkeley: University of California Press, 1973. (History of the world economy in the twentieth century, v. 4).

KREGEL, J. A. The theory of value, expectations and chapter 17 of The General Theory. In: HARCOURT, G. C.; RIACH, P. A. (Ed.) A 'second edition' of The General Theory, v.1. London: Routledge, 1997.

MANTOUX, E. La paix calomniée ou Les conséquences économiques de M. Keynes. Paris: Gallimard, 1946.

MARSHALL, A. Princípios de economia: tratado introdutório, v.I. São Paulo: Nova Cultural, 1996. (Os Economistas).

MAZZUCCHELLI, F. Os anos de chumbo: economia e política internacional no entreguerras. Campinas: Edições Facamp, 2009.

PASINETTI, L. Growth and income distribution: essays in economic theory. Cambridge: Cambridge University Press, 1974.

SILVA, A. C. M.; SANTOS, C. H. Peering over the edge of the short-period? The Keynesian roots of stock-flow consistent macroeconomic models. Cambridge Journal of Economics, v. 35, p. 105-124, 2011.

SKIDELSKY, R. Keynes. Rio de Janeiro: Zahar, 1999.

SMITH, A. A riqueza das nações: investigação sobre sua natureza e suas causas, v.I. São Paulo: Nova Cultural, 1996. (Os Economistas).

SRAFFA, P. Production of commodities by means of commodities: prelude to a critique of economic theory. Cambridge: Cambridge University Press, 1973.

TEIXEIRA, A. Marx e a economia política: a crítica como conceito. Econômica, v. 2, n. 4, p. 85-109, 2000.

Recebido em: 23/09/2011.

Aceito em: 25/03/2013. 